\title{
South African Journal of Industrial and Organisational Psychology: Annual editorial overview 2015
}

\author{
Authors: \\ Melinde Coetzee ${ }^{1}$ \\ Llewellyn van Zy| ${ }^{2}$ \\ Affiliations: \\ ${ }^{1}$ Department of Industrial \\ and Organisational \\ Psychology, University of \\ South Africa, South Africa \\ ${ }^{2}$ Optentia Research Unit, \\ North-West University, \\ South Africa \\ Correspondence to: \\ Melinde Coetzee \\ Email: \\ coetzm1@unisa.ac.za \\ Postal address: \\ PO Box 392, University of \\ South Africa, Pretoria 0003 , \\ South Africa \\ How to cite this article: \\ Coetzee M., \& Van Zyl, L. \\ (2015). South African \\ Journal of Industrial and \\ Organisational Psychology: \\ Annual editorial overview \\ 2015. SA Journal of Industrial \\ Psychology/SA Tydskrif vir \\ Bedryfsielkunde, 41(1), Art. \\ \#1297, 10 pages. http:// \\ dx.doi.org/10.4102/sajip. \\ v41i1.1297

\section{Copyright:} \\ C 2015. The Authors. \\ Licensee: AOSIS \\ OpenJournals. This work is \\ licensed under the Creative \\ Commons Attribution \\ License.
}

\section{Read online:}

\section{Introduction}

The South African Journal of Industrial Psychology (SAJIP) celebrated its 40th anniversary in the previous year and continuous to provide high-quality scholarly research articles of importance to the study of various areas of specialisation in the field of industrial and organisational psychology (IOP). An extensive study by Porter and Schneider (2014) of the global evolution of the field of industrial and organisational (I-O) psychology indicates a continued strong preference for the traditional term 'industrial and organisational psychology' because of the field's rich history of theory, research and practice in organisational settings. The term 'I-O psychology' denotes a historically sound theory-scientific basis with a broad range of research and practice domains. In the South African context, the research and practice domains in I-O psychology are generally guided by the scope of practice of industrial psychologists. The South African Professional Board for Psychology describes the scope of practice of the industrial psychologist (<http:/ / www.hpcsa. co.za>; HPCSA, 2011) to include the following: (1) applying principles of psychology to the work situation of relatively well-adjusted adults; (2) conducting assessment and utilising assessment practices; (3) facilitating individual and group processes; (4) exercising consumer psychological practices; (5) doing ergonomic evaluations; and (6) performing psychological interventions and short-term therapeutic counselling interventions. These tasks of the industrial psychologist are focused on optimising individual, group and organisational well-being, performance and effectiveness (Coetzee \& Schreuder, in press; Coetzee \& Van Zyl, 2014a).

The SAJIP, as the only I-O psychology publication in Africa, serves as an accredited publication medium for scholars, scientists and practitioners who are interested in publishing original research of relevance and interest to the development of concepts pertaining to this scope of practice domains (Coetzee \& Van Zyl, 2014b). The core focus and scope of the SAJIP are for its publications to ultimately contribute to the success and performance of organisations, the effectiveness of leaders and teams and the well-being of people in the organisation (SAJIP, 2013, p. iii). This focus is in line with the long-standing tradition of IOP to follow the scientist-practitioner model, which has the implied goal of research to influence practice. Porter and Schneider (2014) emphasize in this regard that the key challenge for scholars and practitioners in the I-O psychology field remains whether future research studies and their findings will have increasing impact on managerial practice. The SAJIP 2015 annual review therefore focuses on a brief review of the potential contribution of the publications to the advancement of IOP theory and practice as well as highlighting some important legislative policy factors impacting on the Journal.

\section{Contribution to IOP theory and practice}

A review of the publications published in the SAJIP vol. 41, no. 1 (2015) shows the trend of robust attention to knowledge creation and confirmation in the predominant field of organisational psychology, followed by contributions to the fields of wellness and personnel psychology and, to a lesser extent, psychological assessment, career psychology and consumer psychology. Table 1 (see Appendix) outlines the various manuscript contributions with regard to primary I-O psychology theme, research design, originating research institution and the potential implications of the relevant research to IOP theory and practice.

The research focus areas of the articles that contributed to the field of organisational psychology mostly address aspects concerning human relations in the workplace (i.e. trust, stereotyping, individual-organisational link, attachment or commitment, leader behaviour, paradigmatic lens in studying human relations and work identity). The theme of human relations is highly relevant in the context of a culturally diverse South African society. The role of leaders in influencing employee attitudes and behaviour in the organisation-employee relations sphere seems to remain a popular theme in the annual SAJIP editions when considering that the article by Mester, Visser, Roodt and Kellerman (2003) in SAJIP vol. 29, no. 2 (Leadership style and its relation to employee 

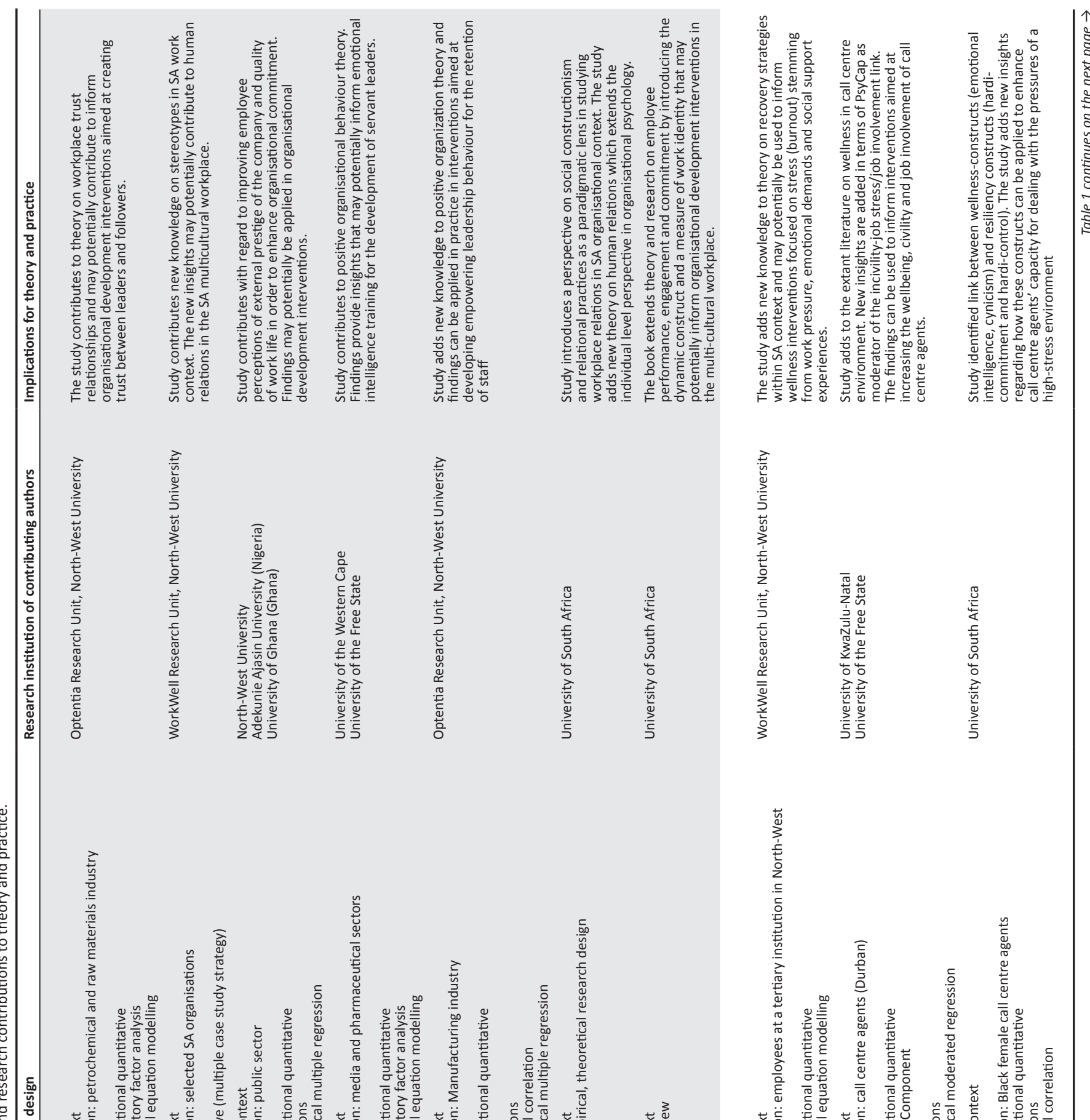

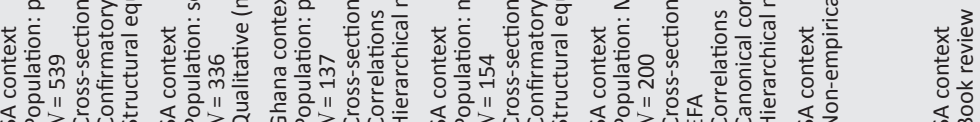

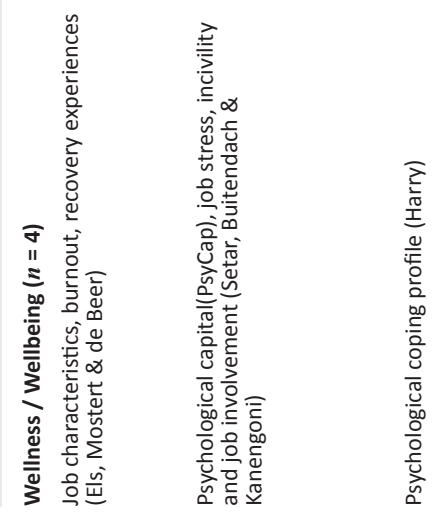




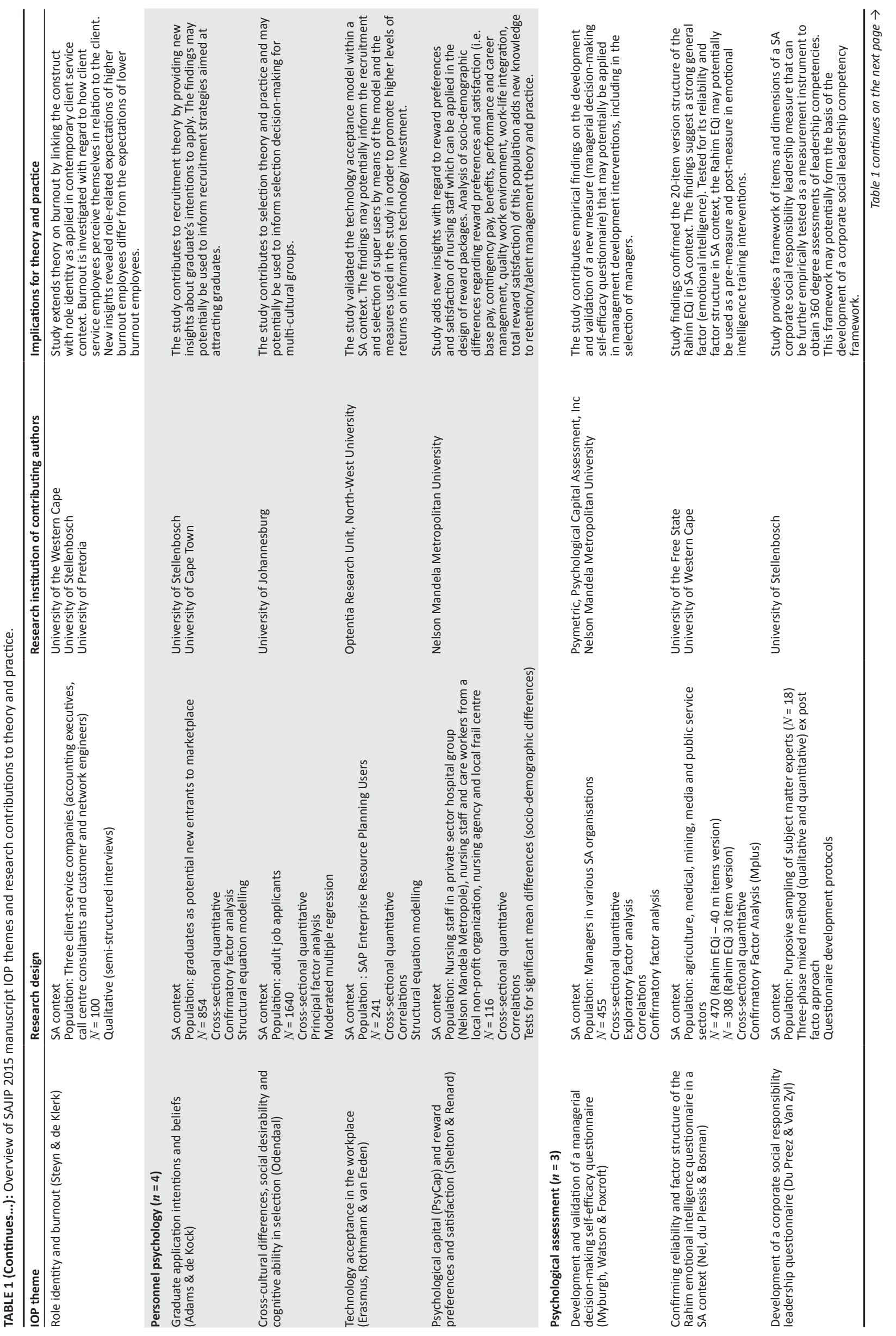




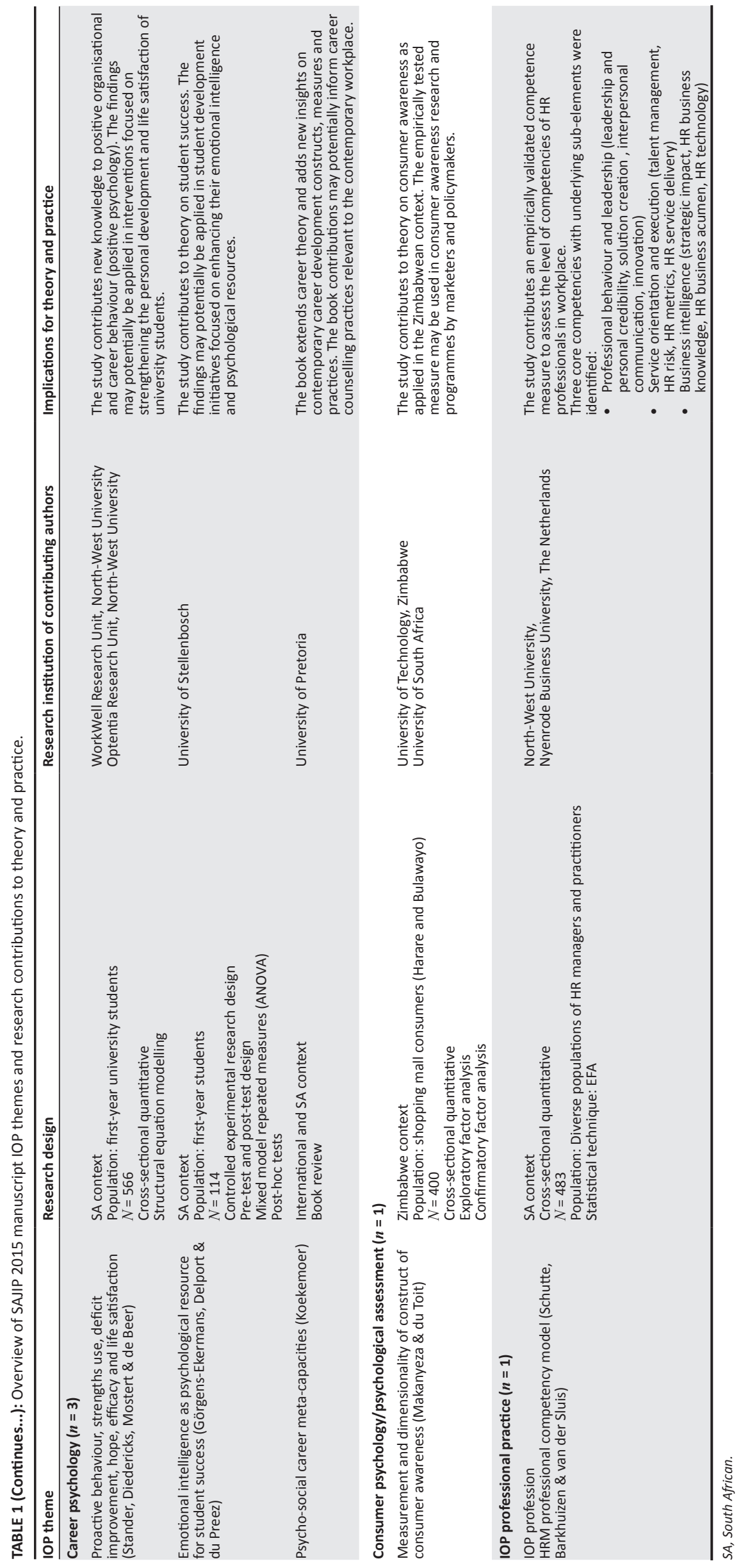


attitudes and behaviour) has to date been the most downloaded article (66 000 downloads) since 2003.

The wellness or and/or well-being-related research themes mostly build on burnout theory and research and extend coping and job stress research by studying wellness constructs (i.e. recovery experiences, PsyCap, emotional intelligence, hardiness, role identity) from the perspective of positive psychology. The notion of positive organisational behaviour theory and research is highly relevant to the contemporary workplace.

The research themes addressed in the articles that contributed to the field of personnel psychology focus on selection and retention factors. The contributions to selection theory and research focus on graduate application intentions and cross-cultural differences with regard to social desirability and cognitive ability. Positive psychology constructs (i.e. PsyCap and satisfaction) are studied in relation to reward preferences of various socio-demographic differences, all of which are highly relevant to the retention of staff. The concept of technology acceptance is also introduced which provides evidence of the increasing role that technology will play in today's work setting.

The psychological assessment research themes contributed empirical evidence of the psychometric properties of three measuring instruments (i.e. a managerial decision-making self-efficacy questionnaire, the Rahim emotional intelligence questionnaire and a corporate social responsibility leadership questionnaire) that can be used in the South African organisational context.

The career psychology research themes are in line with contemporary global trends in the career psychology field to explore positive psychological constructs in enhancing individuals' success and satisfaction (i.e. proactive behaviour, strengths use, deficit improvement, hope, efficacy, life satisfaction, emotional intelligence, psychosocial career meta-capacities).

The consumer psychology research theme made a contribution to not only the field of consumer behaviour but also psychological assessment by presenting the psychometric properties of a measuring instrument in assessing consumer awareness.

The SAJIP vol. 41, no. 1 (2015) edition also showcases a contribution to the IOP profession or practice area with the publication on professional human resource (HR) competencies in the contemporary South African workplace (see Schutte, Barkhuizen, \& van der Sluis). I-O psychologists function also in the HR realm of the business-the competencies outlined in the article of Schutte et al. are therefore very relevant as additional competencies to the current I-O psychology scope of practice specialist competencies. The competencies may potentially be considered in the education and training of the industrial psychologist and HR practitioner.
The populations that were used in the various research articles reflect a variety of industries, including participants from multi-culturally diverse groups. The type of research designs of the articles appearing in the SAJIP vol. 41, no. 1 (2015) edition remains stable when considering previous editions. The predominant research design is the cross-sectional quantitative approach with only three articles following a qualitative research design and one article a mixed-method design. The article by Görgen-Ekermans, Delport, \& du Preez provides a prime example of an evidence-based practice article with its study of an emotional intelligence intervention and data collected about the efficacy of the intervention.

Overall, in line with the SAJIP manuscript guidelines for authors, the SAJIP vol. 41, no. 1 (2015) edition includes predominantly theory-research-practice articles, implying the presentation of foundational theory and theoretical constructs, research questions or hypotheses, participants, measurement, data analysis, results and discussion and implications for practice. In the light of the IOP scientist-practitioner model, it is recommended that future SAJIP editions encourage scholars to critically review the contribution of the theory and research presented by them with regard to a more in-depth discussion on specific techniques, resources or strategies for practice. I-O psychology is seen as "carving a unique identity as a profession in South Africa" and I-O psychologists and scholars contribute to the discipline through scientific research that reflects an evidence-based orientation (as preferred by practitioners) and a commitment to ensuring best practices in the application of psychology in the workplace (Zugec, Garbharran \& Dowdeswell, 2015, p. 41). Evidently, a closer relationship between the IOP discipline (science) and profession (practitioner) would ensure that both areas develop synchronously in order to ensure effective crosspollination between academia and industry.

The Society for Industrial and Organisational Psychology of South Africa's (SIOPSA) annual conference is one avenue through which evidence-based research practices are showcased and effective cross-pollination between the discipline and profession manifests. The associative oral presentation and research themes presented at the conference could provide an indication of the latest practicefocused areas of interest within the profession (Moyo, 2012). Comparison of the publication themes of SAJIP with those of the SIOPSA conference may provide insight into the (mis)alignment between the scientist and the practitioner. Table 2 provides a summary of the SIOPSA's 17th Annual Conference IOP presentation themes (SIOPSA, 2015).

A relative descriptive comparison between the publications in SAJIP and the oral presentations within the SIOPSA conference (see Table 3) indicates that there may be a potential misalignment between the discipline and the profession within the 2015 cycle. Only the organisational psychology (SAJIP: $f=30.43 \%$; SIOPSA: $f=37.04 \%$ ) and consumer psychology or psychological assessment (SAJIP: $f=4.35 \%$; SIOPSA: $f=1.85 \%$ ) themes enjoyed relatively 
TABLE 2: Overview of SIOPSA's 17th Annual Conference IOP paper presentation themes.

\section{IOP theme}

Research institution of contributing authors

IOP professional practice $(\boldsymbol{n}=9)$

Ethics issues in consulting psychology: Different shades of Grey (van Vuuren)

Future fit and Ethics (Guest \& Meiring)

Crafting an Examined Personal Stance as a Work Psychologist: Who am I and What do I Stand for? (Veldsman)

From Self-Serving to Purpose-Driven Professionals: In Pursuit of an Envisioned Legacy. (Veldsman)

Moving IO Psychologists into the role of Transformational Business Partner: Practical Learnings. (Long)

Industrial/Organisational Psychology for the 21st Century: Finding, Absorbing and Radiating Light (Rothmann)

A Critical Review of two decades of Qualitative Research in Psychology, IOP and HRM in South Africa. (O'Neil \& Koekemoer)

The Industrial Psychologist as Mental Skills Coach in Sport: Proposing a Strength Based Philosophy. (Stander)

Training Opportunities for Registration as a Registered Counsellor or Psychometrist in South Africa.

(Van Eeden, Van Deventer \& Erasmus)

Wellness / Wellbeing $(n=4)$

Thriving: Mental Fitness for the Corporate Athlete. (Kruger)

Job Demands \& Resources as Antecedents of Work Engagement; A Diagnostic Survey of Nursing Staff. (D’Emiljo \& Du Preez)

An Investigative Study into the understanding of Mental Toughness in the deployment area. (Schoemann)

Psych Need Satisfaction, Engagement, Turnover Intention of Teachers: Effect of School Principal. (Fouche \& Rothmann)

Forensic psychology $(n=1)$

The IOP Expert Witness in Court: Some Things I wish I had known as an Emerging Expert Witness (Donaldson)

Coaching psychology $(n=1)$

Systems Psychodynamic Coaching - Focusing on Vertical and Horizontal Relationships (Cilliers)

Organisational psychology $(n=20)$

Humanitarian Work Psychology (HWP): A Roundtable Discussion on Using Organisational Psychology for the Greater Good (Meyer, Veldsman \& Renard)

Breaking through Tradition: The Meaning of Work for Women Leaders (Mayer, Surtee \& May)

Exploring decision-making in cross-cultural management teams. (Koornhof)

Big Data Requires Big Judgement - Exploring the Role of Insight IQ for the Organisations Knowledge. (Pleaner)

Towards Flourishing Institutions (Rothmann)

Organisational Culture Deterrent or Retention Tool? (Stadler \& Letchima)

Conflict Resolution Style Preference and Emotional Intelligence. ((Levie \& Isreal)

A Case Study: Using Innovative Workshops to Grow Team Motivation after Restructuring in a Mine. (Long)

Psychological Ownership, Work Engagement and Happiness: How are they related? (Olckers \& George)

Minimizing exposure to behavioural risk of bank tellers. (Bergh)

The Implementation of a Leadership Succession Project in a Large Corporate Organisation. (Dannheimer)

Designing and Implementing a Blended Leadership Development Experience for Succession Candidates. (Conradie \& Visser)

Mental models and ineffective leadership behaviour in South African management practice: a theory of action perspective. (Johnson)

The Relative Importance of Various Predictors of Intention to Quit among South African Employees.

(Stevens, Goodman \& Kock)

Business Driven Action Learning: A Systemic Model for Learning within a State Owned Company (Pillay)

Moving from Integrated Talent Management to Enterprise Talent Management: A Case Study from Illovo (Pleaner \& Banks)

People as THE key element in responding to Business Challenges of the Digital Economy. (Craffert \& Visser)

A Case Study: The Design and Implementation of a Comprehensive Leadership Measurement Framework. (De Klerk \& Teasdale)

Is Strategic Potential all about Cognition? (Distiller)

Are Diversity Programmes Worth it? Understanding Employee Perceptions of LGBT Diversity Programmes in the Workplace. (Grant \& Huntington)

Ergonomics and sustainability $(n=1)$

Hybrid Electric Vehicles: Driving Towards Sustainability. (Riga \& Thatcher)

Career psychology $(\boldsymbol{n}=\mathbf{2})$

Psychobiographical analyses of Entrepreneurs [4]: The Career Development of Albert Wessels (1908-1991). (Van Niekerk \& Fouche)

Organisational Interventions that facilitate the career success of Black South African employees. (Roux \& Malan)

Psychological assessments $(\boldsymbol{n}=14)$

The Validation of a Decision-Making Style Inventory: The JvR Impuls (Voster)

The real cost of English Functional Illiteracy (Pretorius \& Uys)

The Evaluation of Predictors of Two Subjective Career Success Instruments (du Toit, Koekemoer, Nel \& Bester)

Implementing Assessment Strategies Globally: Special reference to Africa. (Kriek)

Employment Equity Act Amendments and the Relevance of Assessment Centres in an Emerging Market (Gericke)

The Practical Implementation of Supervised Online Assessments for Entry-level Test Takers Implications and Solutions (de Wet)

A Case Study in the use of Development Centres to Assess Behaviour at Multiple Levels of Complexity. (Pleanery)

Online Assessment: Contributions of Technology to Best Practice Psychometric Testing. (Lewis)

Ethics South Africa

TTS, University of Pretoria

University of Johannesburg

University of Johannesburg

CEB

Optentia Research Unit, North-West University University of Pretoria

Optentia Research Unit, North-West University University of South Africa

BIOSS

University of Stellenbosch

SANDF

Optentia Research Unit, North-West University

Barbara A. Donaldson, Inc

University of South Africa

University of Cape Town, University of Johannesburg, NMMU

University of South Africa

$\mathrm{EOH}$

CEB

Optentia Research Unit, North-West University TTS, South African Taxi Association WITS

CEB

University of Pretoria

CEB

TTS

TTS

Eskom

University of Cape Town

Eskom

CEB, Illovo

University of the Western-Cape

University of Stellenbosch, Eskom BIOSS

CEB

WITS

The Role of the Psychometrist in Unsupervised Online Assessment. (Guest)

Table 2 continues on the next page $\rightarrow$

NMMU

University of Stellenbosch

JvR Psychometrics

$\mathrm{EOH}$, Kaleidoprax

North-West University,

University of Pretoria, CEB

TTS / University of South Africa

EOH Human Capital Solutions

TTS

CEB

TTS

TTS 
TABLE 2 (Continues...): Overview of SIOPSA's 17th Annual Conference IOP paper presentation themes.

\begin{tabular}{ll}
\hline IOP theme & Research institution of contributing authors \\
\hline Effective Competency Design and Assessment Centre Practices for Leadership in an Emerging Market. (Gericke) & EOH Human Capital Solutions \\
Moving beyond Assumptions through real-life application of Psychometric Data. (Olivier \& Visser) & CEB \\
The Construct Validity of a Learning Styles Inventory in South Africa: How You Learn Inventory. (Voster) & JvR Psychometrics \\
$\begin{array}{l}\text { The Focus of Organisations Moving from Competency Based Measurement to Business Strategy Assessment. } \\
\text { (Kriek \& Wilhelm) }\end{array}$ & TTS \\
The Psychometric Properties of the Experience of Work and Life Circumstance. (Kekana \& Schaap) & University of Pretoria \\
Consumer psychology/psychological assessment ( $\boldsymbol{n}=\mathbf{1})$ & Consultant \\
Observations on the Broader Shifts seen from Business-Led to Consumer-Led Innovations (Chantell Ilbury) & University of South Africa \\
Neuro-psychology ( $\boldsymbol{n}=\mathbf{1}$ ) &
\end{tabular}

TABLE 3. Comparison of relative frequency of themes in SAJIP vs. SIOPSA's 17th Annual Conference.

\begin{tabular}{|c|c|c|c|}
\hline SAJIP theme & Relative frequency in $\%$ & SIOPSA themes & $\begin{array}{l}\text { Relative frequency } \\
\text { in } \%\end{array}$ \\
\hline Organisational psychology $(n=7)$ & 30.43 & Organisational Psychology $(n=20)$ & 37.04 \\
\hline Wellness / Wellbeing $(n=4)$ & 17.39 & Wellness/Wellbeing $(n=4)$ & 7.41 \\
\hline Personnel psychology $(n=4)$ & 17.39 & Personnel psychology $(n=0)$ & 0 \\
\hline Psychological assessment $(n=3)$ & 13.04 & Psychological assessment $(n=14)$ & 25.93 \\
\hline Career psychology $(n=3)$ & 13.04 & Career psychology $(n=2)$ & 3.7 \\
\hline Consumer psychology/psychological assessment $(n=1)$ & 4.35 & Consumer psychology/psychological assessment $(n=1)$ & 1.85 \\
\hline IOP Professional Practice $(n=1)$ & 4.35 & IOP Professional Practice $(n=9)$ & 16.67 \\
\hline- & - & Neuro-psychology $(n=1)$ & 1.85 \\
\hline- & - & Ergonomics and Sustainability $(n=1)$ & 1.85 \\
\hline- & - & Coaching psychology $(n=1)$ & 1.85 \\
\hline - & - & Forensic psychology $(n=1)$ & 1.85 \\
\hline
\end{tabular}

the same amount of attention within the 2015 cycle. Interestingly, popular academic (Coetzee \& Van Zyl, 2014a) and practitioner (Moyo, 2012) IOP research and presentation themes that dominated the last decade within South Africa, such as wellness or wellbeing (SAJIP: $f=17.39 \%$; SIOPSA: $f=7.41 \%$ ) and career psychology (SAJIP: $f=13.04 \%$; SIOPSA: $f=1.85 \%$ ) received less attention in both domains.

From an academic perspective, personnel psychology research (SAJIP: $f=17.39 \%$; SIOPSA: $f=0 \%$ ) increased dramatically as opposed to the 2014 publication cycle within SAJIP (Coetzee \& Van Zyl, 2014a, 2014b) and received no attention within the SIOPSA conference. Similarly, research on psychological assessment measures, techniques and approaches (SAJIP: $f=13.04 \%$; SIOPSA: $f=25.93 \%$ ) as well as IOP professional practice (SAJIP: $f=4.35 \%$; SIOPSA: $f=16.67 \%$ ) themes seemed to be more popular within the practitioner sphere than within the academic domain. Similarly, emerging psychological practice areas such as neuro-psychology, ergonomics and sustainability, coaching psychology and forensic psychology (SAJIP: $f=0 \%$; SIOPSA: $f=1.85 \%$ ) featured within the SIOPSA conference. None of these areas have been covered in the most recent edition of the SAJIP. However, the SIOPSA themes are aligned to trends within the early part of the last decade within both SAJIP (Coetzee \& Van Zyl, 2014a) as well as high impact international journals (Cascio \& Aguinis, 2008). The profession may only now be catching up to the 'latest' research trends of 2004. Morris, Wooding and Grant (2011) indicate that there is a significant time lag of up to 17 years in translating research into practice. As such, practitioners may be slow in their adoption of cutting edge research trends
(Grimshaw, Eccles, Lavis, Hill \& Squires, 2012) which could explain the significant difference between the areas covered in SAJIP and the SIOPSA conference. This does, however, present various unique challenges and opportunities for the SAJIP that could be explored as part of its strategy to enhance its impact to stimulate an increase in its citation ratios and to stay relevant.

In summation, the future is not without its challenges. It is imperative for IOP scholars, scientists and practitioners to ensure that their research areas and practice domains remain relevant. They should keep an open mind for interdisciplinary collaboration, innovations, and application of I-O psychology research and theory on the practice of IOP in the fast-changing global and local economy. Collaboration amongst scholars, scientists and practitioners to integrate theory, research and practice innovations will help to move the field forward and maintain its energy and dynamism over time.

\section{Changes in the DoHET research output policy: Implications for SAJIP}

On the 11 March 2015, the Department of Higher Education and Training (DoHET) published the new Research Outputs Policy [ROP] (DoHET, 2015a) which will take effect on 01 January 2016 (DoHET, 2015b). The DoHET has been mandated to manage the implementation of South Africa's drive to develop into a knowledge-based economy. As such, the DoHET is the body which is responsible for the implementation, allocation and management of the research output subsidy system through the ROP within South Africa. 
The policy is an extensive update from the original Research Outputs of Higher Education Institutions policy, which was published in 2003 (DoHET, 2003). The overall purpose of the ROP (DoHET, 2015a) is to facilitate the publication of higher quality, as opposed to quantity, research outputs and to empower higher education institutions to facilitate such through public funding or subsidy. At its core, the policy aims to provide guidelines on the measurement and evaluation of research outputs in line with the implementation of the DoHET's mandate.

Although the ROP's (DoHET, 2015a) policy framework provides more structured and measurable criteria for the evaluation of research outputs, a number of the proposed changes will affect the publication of scientific journals within South Africa. As custodians for research in the field of industrial and organisational psychology within South Africa (Coetzee \& Van Zyl, 2014a), the South African Journal of Industrial Psychology (SAJIP) needs to inform its constituents of the proposed changes and its possible impact on the publication process. Table 4 highlights the new provisions within the policy and the possible implications for SAJIP.

\section{Concluding remarks: SAJIP annual review 2015}

The focus during the next five years would be to enhance the international exposure of the SAJIP as well as to enhance its impact and span (through increased international citations). One envisioned strategy would be to pull more international researchers to publish within the Journal by involving the SAJIP's national and international board members more actively in developing the strategic direction of the Journal. In this regard, the SAJIP welcomed new additional board members:

\section{National board}

- Prof. Mark Bussin - University of Johannesburg, Optentia Research Unit (North-West University), South Africa

- Dr. Rica Viljoen - Mandala Consulting Group (Pty) Ltd, South Africa

- Dr Steve Bluen - University of Witswatersrand, South Africa

\section{International board}

- Prof. Peter Cappelli - University of Pennsylvania, United States of America

- Prof. Elias Mpofu - University of Sydney, Australia

- Prof. Lize (A.E) Booysen - Antioch University, United States of America

- Prof. Mike Aamodt - Radford University, United States of America

- Prof. Jerome Rossier - University of Lausanne, Switzerland

Similarly, the SAJIP's national operational editorial board have also increased in capacity. The SAJIP editorial board are privileged to welcome another two research methodologists to the section editor team, Dr. Leon De Beer (NWU, Potchefstroom) and Prof. Matthew Cole (Lawrence Tech University, USA).

The SAJIP is privileged to welcome individuals with such impact and influence to the SAJIP editorial team, and national and international boards. The Journal's editorial board will aid the editorial team to uphold and maintain SAJIP's stature as one of Africa's premier Industrial Psychology journals, in line with international standards and compliance to the revised South African research output policy. Although the ROP (DoHET, 2015a) provides clarity on important matters which were previously open to interpretation, it has introduced significant changes which may impact the research behaviour of individuals and the function of academic journals within the South African context. Although only new aspects directly impacting on the Journal were highlighted in this editorial, it is suggested that researchers and scholars from academic institutions carefully study the contents of the ROP (DoHET, 2015a) as various provisions may have serious implications for stakeholders. However, the editorial team believes that the ROP (DoHET, 2015a) is a valuable document which may lead to higher quality research outputs and evidently contribute to enhancing the stature of science within the South African context.

The SAJIP 2015 mid-year report (AOSIS, 2015) shows that the journal attracted during 201554815 new visitors, with 18041 returning visitors. The visitors originated mostly from the following countries: Africa (18 628 new visitors, 10658 returning visitors), America (8852 new visitors, 1297 returning visitors), Europe (9484 visitors, 2297 returning visitors), Asia (15 517 visitors, 3350 returning visitors) and Oceania (2334 new visitors, 439 returning visitors). The SAJIP had 3246872 downloads in total since 2009 and received 210 citations since 2015. As a further testament to the impact and span of the SAJIP, its Scopus impact factor has dramatically increased during the past three years and the Journal will be taken up in a new Thomas Reuter Indexer during the 3rd quarter of the 2015 cycle.

For more than 70 years (since 1945), researchers and scholars globally have been contributing to the I-O psychology literature and, in South Africa, the SAJIP has been a major role player since 1974 (41 years) in that evolution. It is evident from the past SAJIP editions and, again, from the present edition, that the extant literature and research in the I-O psychology domain as represented by the publications continue to present valuable insights into a vibrant discipline and its practice. The editors would like to express their sincere gratitude toward the scholars who continue to submit high-quality manuscripts to the SAJIP in order to evolve the South African perspective on I-O psychology, the reviewers who assist with the review of manuscripts and, most importantly, the section editors of the SAJIP who selflessly devote their time and energy to the peer review process. Their contributions to the SAJIP are highly valued!

The Editorial Board would also like to issue a special word of thanks to AOSIS, the publishers of the Journal, the system 
TABLE 4. Provisions of the DoHET Research Output Policy (2015a): Implications for SAJIP.

\begin{tabular}{ll}
\hline Provision No. & ROP provision wording \\
\hline 2.1 & "The focus of policy must be on growing research and innovation, \\
& improving the quality of research, ensuring coherence of the policy \\
frameworks guiding these areas across the higher education and research & communities and strengthening particular areas identified as important \\
& for national development."
\end{tabular}

Implication for SAJIP

As part of SAJIP's strategic direction (Coetzee \& Van Zyl, 2013), a greater emphasis has been placed on the quality of manuscripts. A number of initiatives have already been implemented to assist in this regard: (a) increased number of operational editorial staff to enhance capacity, (b) diversification of the national and international editorial board, (c) employing methodological and statistical consulting editors, (d) increasing international exposure of the journal through special editions, (e) increasing the number of international peer-reviewers, (f) employing stricter publication guidelines and (d) implementing initiatives to upskill roving strict

"As a general rule, research output emanating from commissioned research or contracts paid by contracting organisations will not be subsidised by the Department"

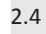

"Peer Review is understood to be the pre-publication refereeing or evaluation of complete manuscripts by independent experts in the field in order to ensure quality and determine whether manuscripts are publishable or not. Additional proxies to determine quality, such as bibliometric data, discipline specific panels of experts and post-publication reviews may in future be utilised by the Department"

2.5 "Research outputs published electronically may be recognised if the publications meet the specified criteria outlined in this policy"

2.7 "The policy does not support differentiation within types of output, for instance, all journal outputs receive the same level of subsidy irrespective of whether they are published internationally or locally. In future, however, the Department may consider introduction of such measures as 'high' or 'low' impact journals; citation indexes or other relevant and appropriate quality measurements after due and extensive consultative process with the sector"
Authors need to state potential conflict of interest and indicate whether research has been commissioned by other parties. Although this practice is not as prominent in the field of IOP as in Medicine, the SAJIP has taken a stance on ensuring objectivity and transparency in relation to the publication process.

Although the SAJIP has strict double-blind peer review processes, the national and international editorial boards are utilised to aid in providing post publication feedback. This practice has been utilised since 2001.

All the specified criteria outlined in the policy are currently being met.

SAJIP is currently in the evaluation process for a Web of Science listin However, the Journal's Google Scholar and Scopus impact factors have dramatically increased during the past 2 years, which provides an indication of the quality and impact of the publications. A number of other initiatives have already been implemented to assist in this regard: (a) increased number of operational editorial staff to enhance capacity, (b) diversification of the national and international editorial boards, (c) employing methodological and statistical consulting editors, (d) increasing international exposure of the and statistical consulting editors, (d) increasing international exposure of the peer-reviewers, (f) employing stricter publication guidelines and (d) implementing initiatives to upskill reviewers. Further, the focus of the SAJIP in implementing initiatives to upskill reviewers. Further, the focus of the SAJIP in the 2016 cycle would be to enhance its international impact through focusing on increasing its citation ratios. A number of activities to this effect is currently being developed. Finally, as a testament to the impact and span of the Journal, its Scopus impact factor has dramatically increased during the past three years and the Journal will be taken up in a new Thomas Reuter Indexer during the 3rd quarter of the 2015 cycle.

Sophisticated plagiarism and self-plagiarism software is employed by the Journal to aid in the identification of recycled publications. A strict rejection policy is applied to instances where plagiarism is detected.

The Journal is listed on various international research indexes in line with the DoHET (2015b), such as Scopus and SciELO SA. Further, the Journal is also to be taken up in a new Thomas Reuter index during the third quarte of 2015 . AOSIS has been instrumental in the indexing of the Journal in these indexes, implying SAJIP's compliance with the DoHET (2015b) in this requirement.

Although SAJIP complies with all of these criteria, it is important to note that the Journal is exempt from the stipulated requirements in Section 5.10 as a result of its listing in the following indices, in accordance with the DoHET (2015b): Scopus and SCiELO SA. The Journal has, however, to comply with the strict requirements of these indices in order to stay indexed. Further, the Journal is to be taken up in Thomas Reuter's new Indexer as of the 3rd Quarter of 2015. Our publisher, AOSIS, has also initiated the process of having the Journal listed in both the IBSS as well as the Norwegian Lists. relevant subject area (b) Articles accepted for publication in the journal must be peer reviewed (c) At least $75 \%$ of contributions published in the journal must emanate from multiple institutions,

(d) The journal must have an International Standard Serial Number (ISSN); (e) The journal must be published at the frequency it is intended to be published, e.g. quarterly, biannually, annually or biennially;

(f) The journal must have an editorial board, with more than two-thirds of the editorial board members beyond a single institution, and which is reflective of expertise in the relevant subject area

(g) The journal must be distributed beyond a single institution; and (h) Journals must include English abstracts if their language of publication is non English.

5.18 The Department encourages the development of local language journals.

6.8

Evidence of the pre-publication peer review process must be provided for every book or chapter submitted for subsidy. The peer-review evidence must be clear and unambiguous.

SAJIP accepts publications in both English and Afrikaans.

Although this provision relates to specialist books and specialist chapters, the SAJIP has adopted a developmental approach to upskilling and empowering researchers through peer-reviews. Comprehensive peer-review reports are submitted to each author upon completion of the double-blind peer review process. The SAJIP online web system keeps track of every activity associated with the peer-review process in order to ensure the authenticity and transparency of the peer-review process for auditing purposes. administrators, Duncan Hooker and Kyle Paulse, for the efficient support provided to SAJIP authors, editors, section editors and reviewers, and specifically Ms. Trudie Retief for managing the processes associated with the Journal's listing in the high ranking international indices. Specifically, the Board's gratitude is expressed for the Journal's listing in the new Thomas Reuter Index list during the 3rd quarter of this year. Finally, reflecting on the SAJIP's achievements over the years and the year of 2015, the Board feels confident that the SAJIP will only grow from strength to strength!

\section{Acknowledgements Competing interests}

The authors declare that they have no financial or personal relationships which may have inappropriately influenced them in writing this article. 


\section{Authors' contributions}

Prof Melinde Coetzee wrote up the editorial review. Prof Llewellyn van Zyl contributed extensively to the content of the editorial review.

\section{References}

AOSIS. (2015). Journal second quarter 2015 report SAJIP. Cape Town: AOSIS Openjournals.

Cascio, W.F., \& Aguinis, H. (2008). Research in industrial and organizational psychology from 1963 to 2007: Changes, choices, and trends. Journal of Applied Psychology, 93(5), 1062-1081. PMID: 18808226, http://dx.doi.org/10.1037/0021 9010.93.5.1062

Coetzee, M., \& Schreuder, A.M.G. (in press). Personnel psychology: An applied perspective. (2nd edn.). Cape Town: Oxford University Press.

Coetzee, M., \& Van Zyl, L.E. (2013). Advancing research in industrial and organisational psychology - A brief overview of 2013. SA Journal of Industrial Psychology/SA Tydskrif vir Bedryfsielkunde, 39(1), Art. \#1174, 4 pages. http://dx.doi.org/10.4102/ sajip.v39i1.1174

Coetzee, M., \& Van Zyl, L.E. (2014a). A review of a decade's scholarly publications (2004-2013) in the South African Journal of Industrial Psychology. SA Journal of Industrial Psychology/SA Tydskrif vir Bedryfsielkunde, 4O(1), Art. \#1227, 16 pages. http://dx.doi.org/10.4102/ sajip.v40i1.1227

Coetzee, M., \& Van Zyl, L.E. (2014b). South African Journal of Industrial Psychology: Annual editorial overview 2014. SA Journal of Industrial Psychology/SA Tydskrif vir Bedryfsielkunde, 4O(1), Art. \#1245, 5 pages. http://dx.doi.org/10.4102/sajip. v40i1.1245

Department of Higher Education and Training (DoHET). (2003). Research outputs of higher education institutions. Retrieved from http://goo.gl/cOITOB
Department of Higher Education and Training (DoHET). (2015a). Research outputs policy. (Government Gazette 38552, Notice 188, 11 March 2015). Pretoria, South Africa: Government Printer.

Department of Higher Education and Training (DoHET). (2015b, August). Directorate: University Policy and Development Support. Communiqué 2 of 2015 - Research Output Policy. Pretoria, South Africa: Government Printer.

Grimshaw, J.M., Eccles, M.P., Lavis, J.N., Hill, S.J., \& Squires, J.E. (2012). Knowledge translation of research findings. Implement Sci, 7(1), 50-57. PMID: 22651257 $\mathrm{http}: / / \mathrm{dx}$.oi.org/10.1186/1748-5908-7-50

Health Professions Council of South Africa (HPCSA). (2011). Regulations defining the scope of practice of practitioners of the profession of psychology: Proposed regulation No. R. 263. Retrieved from http://www.psyssa.com/documents/ Letter $\% 20$ to $\% 20$ Psychologists $\% 2021 \% 20$ August $\% 202011$ pdf.pdf

Mester, C., Visser, D., Roodt, G., \& Kellerman, R. (2003). Leadership style and its relation to employee attitudes and behaviour. South African Journal of Industrial Psychology, 29(2), 72-82.

Morris, Z.S., Wooding, S., \& Grant, J. (2011). The answer is 17 years, what is the question: Understanding time lags in translational research. Journal of the Royal Society of Medicine, 104(12), 510-520. PMID: 22179294, http://dx.oi. org/10.1258/jrsm.2011.110180

Moyo, N.T. (2012). Industrial and organisational psychology in South Africa: Research and practice. Unpublished masters dissertation, University of the Witwatersrand Johannesburg, South Africa.

Porter, L.W., \& Schneider, B. (2014). What was, what is, and what may be in OP/OB Annual Review of Organizational Psychology and Organizational Behavior, 1 , 1-21. http://dx.oi.org/10.1146/annurev-orgpsych-031413-091302

SAJIP. (2013). Information for authors and readers of the SA Journal of Industrial Psychology. South African Journal of Industrial Psychology, 39(1), iii.

Society for Industrial and Organisational Psychology of South Africa (SIOPSA). (2015) Breaking through tradition: 10 psychology for the 21st century. The 17th annual SIOPSA Conference abstract book. Retrieved from https://www.siopsa.org.za/ news_articles/view/92

Zugec, L., Garbharran, A., \& Dowdeswell, K. (2015). Showcasing I-O psychology in South Africa. International Practice Forum, 52(4), 36-42. 